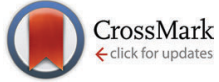

Cite this: Phys. Chem. Chem. Phys., $2014,16,22651$

\section{In situ X-ray Raman spectroscopy study of the hydrogen sorption properties of lithium borohydride nanocomposites $\dagger$}

\author{
Piter S. Miedema, $\ddagger^{* a}$ Peter Ngene, $\S^{a}$ Ad M. J. van der Eerden, ${ }^{a}$ \\ Dimosthenis Sokaras, ${ }^{b}$ Tsu-Chien Weng, ${ }^{b}$ Dennis Nordlund, ${ }^{b}$ Yuen S. Au ${ }^{a}$ and \\ Frank M. F. de Groot ${ }^{a}$
}

\begin{abstract}
Nanoconfined alkali metal borohydrides are promising materials for reversible hydrogen storage applications, but the characterization of hydrogen sorption in these materials is difficult. Here we show that with in situ X-ray Raman spectroscopy (XRS) we can track the relative amounts of intermediates and final products formed during de- and re-hydrogenation of nanoconfined lithium borohydride $\left(\mathrm{LiBH}_{4}\right)$ and therefore we can possibly identify the de- and re-hydrogenation pathways. In the XRS of nanoconfined $\mathrm{LiBH}_{4}$ at different points in the de- and re-hydrogenation, we identified phases that lead to the conclusion that de- and re-hydrogenation pathways in nanoconfined $\mathrm{LiBH}_{4}$ are different from bulk $\mathrm{LiBH}_{4}$ : intercalated lithium $\left(\mathrm{LiC}_{x}\right)$, boron and lithium hydride were formed during de-hydrogenation, but as well $\mathrm{Li}_{2} \mathrm{~B}_{12} \mathrm{H}_{12}$ was observed indicating that there is possibly some bulk $\mathrm{LiBH}_{4}$ present in the nanoconfined sample $\mathrm{LiBH}_{4}-\mathrm{C}$ as prepared. Surprisingly, XRS revealed that the de-hydrogenated products of the $\mathrm{LiBH}_{4}-\mathrm{C}$ nanocomposites can be partially rehydrogenated to about $90 \%$ of $\mathrm{Li}_{2} \mathrm{~B}_{12} \mathrm{H}_{12}$ and $2-5 \%$ of $\mathrm{LiBH}_{4}$ at a mild condition of 1 bar $\mathrm{H}_{2}$ and $350{ }^{\circ} \mathrm{C}$. This suggests that re-hydrogenation occurs via the formation of $\mathrm{Li}_{2} \mathrm{~B}_{12} \mathrm{H}_{12}$. Our results show that XRS is an elegant technique that can be used for in and ex situ study of the hydrogen sorption properties of nanoconfined and bulk light-weight metal hydrides in energy storage applications.
\end{abstract}

Received 3rd July 2014, Accepted 10th September 2014

DOI: $10.1039 / c 4 c p 02918 f$

www.rsc.org/pccp

\section{Introduction}

Hydrogen has the potential to play a vital role in future sustainable-energy scenarios. ${ }^{1}$ It can be produced in a sustainable way from water using solar, wind and geothermal energy; and also via catalytic conversion of biomass. Hydrogen has the highest gravimetric energy density and can be used in

\footnotetext{
${ }^{a}$ Department of Inorganic Chemistry and Heterogeneous Catalysis, Debye Institute for Nanomaterials Science, Utrecht University, Universiteitsweg 99, 3584 CG Utrecht, The Netherlands. E-mail: p.s.miedema@gmail.com

${ }^{b}$ Stanford Synchrotron Radiation Lightsource, SLAC National Accelerator Laboratory, 2575 Sand Hill Road, Menlo Park, CA 94025, USA

$\dagger$ Electronic supplementary information (ESI) available: $\mathrm{Li}_{2} \mathrm{~B}_{12} \mathrm{H}_{12} \mathrm{XRD}$, time evolution $\mathrm{B}$ and Li K-edge XRS spectra, comparison of different fractions of references with the $\mathrm{B}$ and $\mathrm{Li}$ K-edge $\mathrm{XRS}$ of $\mathrm{LiBH}_{4}-\mathrm{C}$ under different conditions, B K-edge XRS experiments and XAS calculations on $\mathrm{NaBH}_{4}$ and $\mathrm{Na}_{2} \mathrm{~B}_{12} \mathrm{H}_{12}$ and the C K-edge XRS of $\mathrm{NaBH}_{4}-\mathrm{C}$ and $\mathrm{LiBH}_{4}-\mathrm{C}$ under different conditions. See DOI: 10.1039/c4cp02918f

\# Present address: Institute for Methods and Instrumentation for Synchrotron Radiation Research G-ISRR, Helmholtz-Zentrum für Materialien und Energie GmbH, Albert-Einstein-Strasse 15, 12489 Berlin, Germany.

$\S$ Present address: Group for Materials for Energy Conversion and Storage, Chemical Engineering, Faculty of Applied Sciences, Delft University of Technology, Julianalaan 136, 2628 BL Delft, The Netherlands.
}

combination with fuel cells to produce electrical energy for automobiles, stationary applications such as power generators and portable electronics. A major challenge that prevents the widespread use of hydrogen as a fuel, is its storage and in particular the storage efficiency, safety and cost. Several methods have been proposed to store hydrogen, including pressurized gas, liquefied hydrogen and hydrogen storage in solids. Among these options, storing hydrogen as metal hydrides is interesting from the view point of safety, energy density and volume density. As the gravimetric density of the material is an important consideration, many studies have focused on hydrides of light-weight elements or alloys such as $\mathrm{MgH}_{2}, \mathrm{LiBH}_{4}, \mathrm{NaBH}_{4}, \mathrm{NaAlH}_{4}$ and $\mathrm{Mg}\left(\mathrm{BH}_{4}\right)_{2}$. Especially, the alkali-metal borohydrides have been widely investigated for reversible hydrogen storage due to their high hydrogen content: ${ }^{1,2}$ for example $\mathrm{LiBH}_{4}$ contains $18.5 \mathrm{wt} \%$ hydrogen. However, these light weight complex hydrides are rather stable and as a consequence they start to release hydrogen only at elevated temperatures $\left(370{ }^{\circ} \mathrm{C}\right.$ for $\left.\mathrm{LiBH}_{4}\right) \cdot{ }^{3,4}$ These temperatures are too high for practical commercial applications. Additionally the hydrogen sorption reaction of the alkali-metal borohydride suffers from poor reversibility.

In an effort to improve the hydrogen storage properties of these complex hydrides, strategies such as nanosizing/nanoconfinement, 
destabilization/product stabilization, addition of suitable catalysts and core shell strategy have been explored. ${ }^{5-15}$ These strategies generally led to an improvement in their hydrogen sorption properties. However, for practical application further improvement of these materials is required. A good understanding of the hydrogenation and de-hydrogenation pathway by measuring the development of different phases during de- and re-hydrogenation of these materials would be beneficial in improving their hydrogen storage properties.

Unfortunately, $\mathrm{LiBH}_{4}$ and many other complex hydrides undergo multiple desorption steps with often amorphous and sometimes volatile intermediates that cannot be characterized using standard techniques such as X-ray diffraction (XRD). Transmission electron microscopy (TEM) is also ineffective due to the weak scattering of electrons by the light elements $\mathrm{Li}$, Na and B. Additionally, confinement of $\mathrm{LiBH}_{4}$ in nanoporous carbon materials, which was shown to be a promising strategy to improve hydrogen release and uptake in these complex hydrides, ${ }^{8,10,11}$ often leads to nanocomposites that are amorphous after preparation. This also complicates the study of the decomposition mechanisms since the starting material and de-hydrogenation products are both amorphous. Additionally, due to light absorption by the carbon scaffold, the use of techniques such as Infrared (IR) and Raman spectroscopy is difficult for these systems confined in nanoporous carbon. Another complication is that the measurements on these complex metal hydrides have to be performed under inert atmosphere, which is another challenging but not impossible requirement for all the above mentioned techniques.

Consequently the exact origin for the enhancements in hydrogen sorption properties and change in thermodynamics or decomposition pathway(s) relative to the bulk that is often observed in nanoconfined complex hydrides, is still not well understood. ${ }^{8}$ To this end theoretical calculations combined with techniques such as NMR and inelastic neutron scattering methods are increasingly being used to study the decomposition mechanism of bulk and nanoconfined metal borohydrides. ${ }^{16-19}$ However using NMR or inelastic neutron scattering, it is very challenging to experimentally follow the decomposition of these metal hydrides by in situ measurements, which would be required to reliably unravel their decomposition reactions, its phases and mechanisms.

In our previous paper we demonstrated the feasibility of X-Ray Raman Spectroscopy (XRS) as a new technique to study the electronic properties of bulk and $\mathrm{LiBH}_{4}$-carbon nanocomposites $\left(\mathrm{LiBH}_{4}-\mathrm{C}\right)$ during de-hydrogenation. ${ }^{20}$ The XRS technique applies tuneable hard X-ray radiation. Hard X-ray (absorption) spectroscopies can be performed in situ and supply element-specific electronic structure information ${ }^{20,21}$ and the main difficulty is that synchrotron radiation is required. In our previous $\operatorname{paper}^{20}$ the presence of oxygen in the gas stream during the experiments had a huge impact on the spectral shape and influenced the interpretation of the results. Nevertheless, it was demonstrated that XRS is a promising tool to study the decomposition mechanism of $\mathrm{LiBH}_{4}-\mathrm{C}$ nanocomposites. Using an in situ cell, this hard X-ray technique allows the probing of the electronic transitions taking place in the boron, lithium and carbon during hydrogen release and uptake from $\mathrm{LiBH}_{4}-\mathrm{C}$ nanocomposites.

For the present research paper we improved the experimental conditions so as to minimize the effect of oxygen by preparing ex situ de-hydrogenated and re-hydrogenated samples and we extended our approach by comparison with reference materials. In addition, we tested this technique to study the decomposition of $\mathrm{NaBH}_{4}-\mathrm{C}$ nanocomposites (shown in the ESI, $\dagger$ Section S10), for which only few literature exists regarding their de-hydrogenation and re-hydrogenation behaviour.

In this paper we show that using XRS, the changes in the electronic properties of $\mathrm{Li}, \mathrm{B}$ and $\mathrm{C}$ during the de-hydrogenation reactions of $\mathrm{LiBH}_{4}$ confined in nanoporous carbon can reliably be measured in situ and the decomposition products can be assigned with reasonable accuracy by comparing with reference materials.

\section{Experimental section}

\section{Reference materials}

The following materials were used as received from the supplier: boron powder (99.5\% pure, crystalline $<20 \mathrm{~mm}, \mathrm{ABCR})$, lithium metaborate $\left(\mathrm{LiBO}_{2}\right)$ powder (99.995\% pure, Aldrich), $\mathrm{B}_{2} \mathrm{O}_{3}$ powder (99.995\% pure, Chempur), lithium hydride ( $\mathrm{LiH})$ powder $(99.4 \%$ pure, 30 mesh, Alfa), lithium borohydride $\left(\mathrm{LiBH}_{4}, 95 \%\right.$ pure, Acros-organics) and sodium borohydride $\left(\mathrm{NaBH}_{4}, 99.99 \%\right.$ trace metals basis, Acros-organics) and lithium metal foil (Li, 99.9\% pure, Sigma-Aldrich). Some of these compounds were used for the sample preparations mentioned below.

\section{Nanoconfined $\mathrm{LiBH}_{4}$ and $\mathrm{NaBH}_{4}$}

To minimize the effect of oxygen, three types of ex situ samples were prepared:

(1) $25 \mathrm{wt} \% \mathrm{LiBH}_{4}-\mathrm{C}$ nanocomposites were prepared by melt infiltration as described previously. ${ }^{10,11}$ In short, 0.25 gram of $\mathrm{LiBH}_{4}$ was mixed with $0.75 \mathrm{~g}$ of nanoporous carbon (High surface area graphite: HSAG-500 provided by Timcal Switzerland, pore volume $0.65 \mathrm{~cm}^{3} \mathrm{~g}^{-1}$, broad pore size contribution, majority of pore sizes is $2-3 \mathrm{~nm}$ ). The $\mathrm{LiBH}_{4}$-porous carbon mixture was heated in an autoclave to $295{ }^{\circ} \mathrm{C}$ with an initial pressure of $50 \mathrm{bar}$ hydrogen. The samples were cooled down under hydrogen pressure and transferred into an argon filled glove box. These samples are further called " $\mathrm{LiBH}_{4}-\mathrm{C}$ as prep".

(2) Part of the $\mathrm{LiBH}_{4}-\mathrm{C}$ as prep sample was de-hydrogenated by heating under $25 \mathrm{ml} \mathrm{min}{ }^{-1}$ argon flow, $5{ }^{\circ} \mathrm{C} \min ^{-1}$ with a dwell time of 30 minutes at the maximum de-hydrogenation temperature $\left(400{ }^{\circ} \mathrm{C}\right.$ for $\left.\mathrm{LiBH}_{4}-\mathrm{C}\right)$. These de-hydrogenated samples are labelled " $\mathrm{LiBH}_{4}-\mathrm{C}$ deh".

(3) Part of the $\mathrm{LiBH}_{4}-\mathrm{C}$ deh was re-hydrogenated by heating in an autoclave to $325{ }^{\circ} \mathrm{C}$ under 60 bar hydrogen for 3 hours. This sample will further on be referred to as " $\mathrm{LiBH}_{4}-\mathrm{C}$ reh".

\section{Preparation of $\mathrm{Li}_{2} \mathrm{~B}_{12} \mathrm{H}_{12}$}

$\mathrm{Li}_{2} \mathrm{~B}_{12} \mathrm{H}_{12}$ was prepared by the reaction between $\mathrm{LiBH}_{4}$ and decaborane:

$$
2 \mathrm{LiBH}_{4}+\mathrm{B}_{10} \mathrm{H}_{14} \rightarrow \mathrm{Li}_{2} \mathrm{~B}_{12} \mathrm{H}_{12}+5 \mathrm{H}_{2}
$$


Stoichiometric amounts of $\mathrm{LiBH}_{4}$ and decaborane $\left(\mathrm{B}_{10} \mathrm{H}_{14}\right)$ were properly mixed and placed into a stainless steel reactor. The reactor was placed in an oven and heated to $420{ }^{\circ} \mathrm{C}$, with a dwell time of $1 \mathrm{hr}$ at $420{ }^{\circ} \mathrm{C}$. The reactor was then cooled down to ambient conditions and a white reaction product was collected and analyzed using X-ray diffraction (XRD). This type of preparation was published before by He et al. ${ }^{22}$ The XRD pattern of the $\mathrm{Li}_{2} \mathrm{~B}_{12} \mathrm{H}_{12}$ prepared in the way mentioned above is shown besides the starting components in the ESI $\dagger$ (Fig. S1) and it shows a Bragg peak around 18 degrees which is observed as well in the $\mathrm{Li}_{2} \mathrm{~B}_{12} \mathrm{H}_{12}$ synthesized by Friedrichs et al. ${ }^{23}$ by reacting $\mathrm{B}_{2} \mathrm{H}_{6}$ and $\mathrm{LiBH}_{4}$ above $200{ }^{\circ} \mathrm{C}$. However Friedrichs also finds a stronger Bragg peak around 15.8 degrees, which would suggest that we don't have pure crystalline, but more likely, that we have synthesized amorphous $\mathrm{Li}_{2} \mathrm{~B}_{12} \mathrm{H}_{12}$. For our purpose of measuring XRS this does not matter much and we actually believe that it is more convenient to have amorphous $\mathrm{Li}_{2} \mathrm{~B}_{12} \mathrm{H}_{12}$ as a reference material.

All samples preparations and handling was conducted in an argon filled glove box (typically $<1 \mathrm{ppm}$ of oxygen and moisture) to avoid contamination. All prepared samples and reference materials mentioned above were sent to the Stanford Synchrotron Radiation Lightsource (SSRL) in an air-tight container and directly brought into an argon filled glove box present at the SSRL.

\section{In situ cell}

The in situ cell used for the XRS measurements has been described elsewhere. ${ }^{20}$ In short, this cell was optimized for a large solid angle of the (high momentum transfer $q$ ) inelastic scattered X-rays through a large exit window. The exit window is wide enough to record both high and low $q$ inelastic scattered $\mathrm{X}$-rays without changing the cell position. For the XRS measurements, samples were pressed in a sample holder and subsequently attached inside the unscrewed in situ cell remaining inside the argon filled glove-box at SSRL. After pressing the sample in the sample holder, the in situ cell was screwed air-tight and the complete in situ cell was taken out of the glove-box and ready for XRS experiments.

\section{X-ray Raman Spectroscopy (XRS) measurements}

In X-ray Raman Spectroscopy (XRS) an incident (hard) X-ray photon is inelastically scattered and part of its energy is transferred to excite an inner shell electron into an unoccupied state. Under the dipole approximation, which is for XRS valid for small forward X-ray scattering angles, the resulting features are identical to the X-ray absorption spectroscopy and the energy loss associated with the inelastic scattering is equal to the X-ray absorption energy. In the case of light elements, where the X-ray edges are in the low soft X-ray energy regime, XRS is a wonderful alternative for X-ray absorption spectroscopy. ${ }^{21}$

Lithium (Li), boron (B) and carbon (C) K-edge XRS were collected at SSRL beamline BL6-2 ES2. ${ }^{24}$ The in situ cell was mounted such that the angle with the beam was the same at every measurement. The XRS measurements were performed using the inverse energy scan technique, i.e., the scattered photons were analysed at fixed energy (here 6462.2 eV) whereas the energy transfer is controlled by tuning the incident photon energy. The XRS spectra were measured in forward scattering angles (low q), using only the four lowest momentum transfer (q) rows of the 40-crystal spectrometer $\left(0.8 \AA^{-1}, 1.2 \AA^{-1}, 1.5 \AA^{-1}\right.$ and $1.9 \AA^{-1}$ respectively). This had two goals: first to minimize the non-dipole contributions within the XRS of the Li K-edge, and secondly to reduce background noise in the B K-edge XRS or in other words to improve the B K-edge XRS signal-to-noise ratio. The background noise reduction is important to obtain more information on changes in the B K-edge after de- and re-hydrogenation compared to our former experiments. ${ }^{20}$ The XRS measurements were plotted as scattered intensity versus energy loss, which is the incident energy minus the elastic energy of the (fixed energy) analyzer and the energy resolution of the XRS spectra was about $0.2 \mathrm{eV}$. During the XRS measurements the in situ cell was under a helium atmosphere flow (99.999\% pure) or in some cases under a hydrogen flow of $10 \mathrm{ml} \mathrm{min}{ }^{-1}$, which was used as a carrier gas.

The Li and B K-edge XRS of reference compounds, bulk $\mathrm{LiBH}_{4}$ and of $\mathrm{LiBH}_{4}-\mathrm{C}$ as prep, deh ex situ and reh ex situ were measured under $10 \mathrm{ml} \mathrm{min}{ }^{-1}$ helium flow. The $\mathrm{LiBH}_{4}-\mathrm{C}$ as prep sample was de-hydrogenated in situ by heating under helium to $370{ }^{\circ} \mathrm{C}$ and the $\mathrm{Li}, \mathrm{B}$ and $\mathrm{C}$ K-edges measured at different temperatures during decomposition. The ex situ de-hydrogenated sample $\left(\mathrm{LiBH}_{4}-\mathrm{C}\right.$ deh) was partially re-hydrogenated in situ by heating under 1 bar of (pure) hydrogen (99.999\%) with a flow of $10 \mathrm{ml} \mathrm{min}^{-1}$. to $370{ }^{\circ} \mathrm{C}$ with a ramp of $10{ }^{\circ} \mathrm{C} \mathrm{min}^{-1}$. and after a dwell time of 30 minutes at $370{ }^{\circ} \mathrm{C}$, the sample was cooled down to room temperature. $\mathrm{Li}$ and $\mathrm{B}$ K-edge XRS measurements were performed at both $370{ }^{\circ} \mathrm{C}$ and at room temperature. Note that we mention that the $\mathrm{LiBH}_{4}-\mathrm{C}$ nanocomposites were only partially re-hydrogenated in this case, since the in situ cell can only handle 1 bar hydrogen and much higher pressures are required for a (close to) full re-hydrogenation.

\section{Results and discussion}

\section{B K-edge XRS of $\mathrm{LiBH}_{4}-\mathrm{C}$}

Fig. 1 shows the B K-edge XRS spectra of $\mathrm{LiBH}_{4}-\mathrm{C}$ as prep, bulk $\mathrm{LiBH}_{4}$ and the $\mathrm{LiBO}_{2}$ reference. The B K-edge of bulk $\mathrm{LiBH}_{4}$

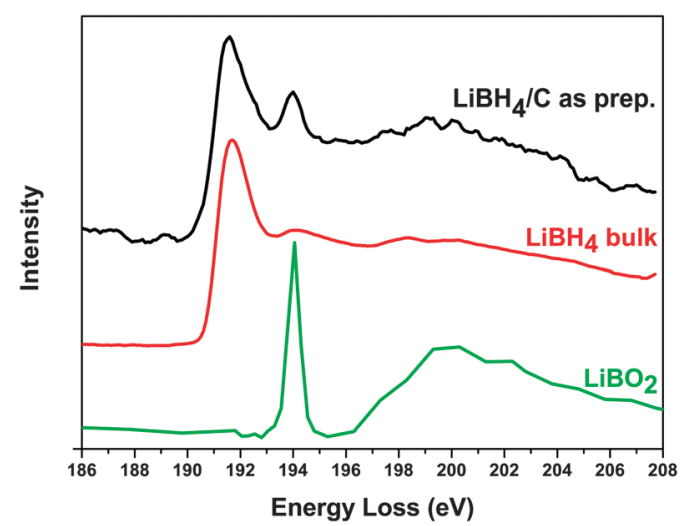

Fig. 1 Boron (B) K-edge XRS of $\mathrm{LiBH}_{4}-\mathrm{C}$ as prepared ( $\mathrm{LiBH}_{4}-\mathrm{C}$ as prep., black) compared to the $\mathrm{B}$ K-edge XRS of bulk $\mathrm{LiBH}_{4}$ powder $\left(\mathrm{LiBH}_{4}\right.$ bulk, red) and lithium metaborate powder ( $\mathrm{LiBO}_{2}$ green). 
powder (red line) and the melt-infiltrated nanoconfined sample $\mathrm{LiBH}_{4}-\mathrm{C}$ as prep (black line) have a similar peak at $191.8 \mathrm{eV}$. This implies that the electronic properties and structure of $\mathrm{LiBH}_{4}$ in the as-prepared $\mathrm{LiBH}_{4}-\mathrm{C}$ nanocomposite remain mostly unchanged, which is in line with literature reports on $\mathrm{LiBH}_{4}$ confined in similar nanoporous carbon material. ${ }^{12,13,25}$ However for $\mathrm{LiBH}_{4}-\mathrm{C}$ as prep, there is also a peak at $194 \mathrm{eV}$ and extra features at higher energy loss which resembles the $\mathrm{B}$ K-edge of $\mathrm{LiBO}_{2}$. There is a variety of oxidic lithium and boron species, but the most stable and therefore relevant ones are $\mathrm{LiBO}_{2}$ and $\mathrm{B}_{2} \mathrm{O}_{3}$. The experimental spectrum of $\mathrm{B}_{2} \mathrm{O}_{3}$ is given in the ESI, $\dagger$ Fig. S4.

The peak at $194 \mathrm{eV}$ in the $\mathrm{LiBH}_{4}-\mathrm{C}$ as prep is already present in the first measurement, but time evolution of the B K-edge XRS (ESI, $\dagger$ Fig. S2) shows that this peak increases with time. Since oxygen was excluded as much as possible during the preparation and handling of the $\mathrm{LiBH}_{4}-\mathrm{C}$ nanocomposite, we attribute the presence of the oxidic boron to possible reactions between traces of carbon surface oxygen groups and $\mathrm{LiBH}_{4}$ at high temperatures during the melt infiltration process for the preparation of the $\mathrm{LiBH}_{4}-\mathrm{C}$ nanocomposites. This is supported by the fact that the $194 \mathrm{eV}$ peak is observed in the first B K-edge measurement already and the time evolution of the $194 \mathrm{eV}$ peak to the $<1 \mathrm{ppm}$ oxygen in the helium carrier gas used for the hydrogen desorption of the $\mathrm{LiBH}_{4}-\mathrm{C}$ nanocomposites. On one side all the B K-edge XRS measurements of reference materials do not show oxygenation after prolonged exposure to X-rays. On the other side, we cannot completely exclude X-ray induced oxidation, since the nanoconfined materials are expected to be more reactive. Recent NMR studies on similar $\mathrm{NaBH}_{4}-\mathrm{C}$ nanocomposites also indicate the presence of minor amounts of $\mathrm{NaBO}_{2}$ in the as-prepared nanocomposites. ${ }^{10}$ The present results show that the $\mathrm{B}$ K-edge XRS is highly sensitive to boron oxides, because the peak at $194 \mathrm{eV}$ is quite intense and already present even when small amounts of oxygen react with the $\mathrm{LiBH}_{4}$. This observation also indicates that the presence of even a trace amount of oxygen could be detrimental to the accurate evaluation of the decomposition mechanism of borohydride since the decomposition pathways and products could be changed. We also measured the oxygen K-edge XRS of some of the samples (see ESI, $\dagger$ Fig. S15) and the results confirm that the increase of the peak at $194 \mathrm{eV}$ is indeed due to oxidation and very likely from a continuing source of oxygen (1 ppm of oxygen in helium or hydrogen flow).

However, based on the B K-edge of the oxygen-containing reference materials, the electronic information below $194 \mathrm{eV}$ in the B K-edge can be used for further analysis on de- and re-hydrogenation and in the further qualitative and quantitative analysis we focus mainly on the B K-edge XRS spectra below $194 \mathrm{eV}$. All the XRS spectra with the full measured B K-edge energy loss range can be found in the ESI $\dagger$ (Fig. S9).

Fig. 2 shows the B K-edge XRS energy loss range till $193 \mathrm{eV}$ of $\mathrm{LiBH}_{4}-\mathrm{C}$ as prep, $\mathrm{LiBH}_{4}-\mathrm{C}$ deh and after partial re-hydrogenation, further called $\mathrm{LiBH}_{4}-\mathrm{C}$ Deh $+\mathrm{H}_{2}$ @RT. We focus first on the differences between the $\mathrm{LiBH}_{4}-\mathrm{C}$ as prep (black) and $\mathrm{LiBH}_{4}-\mathrm{C}$ deh (red). The main peak at $191.5 \mathrm{eV}$ for $\mathrm{LiBH}_{4}-\mathrm{C}$ as prep shifts to lower energy for the $\mathrm{LiBH}_{4}-\mathrm{C}$ deh. This peak was attributed to $\mathrm{LiBH}_{4}$

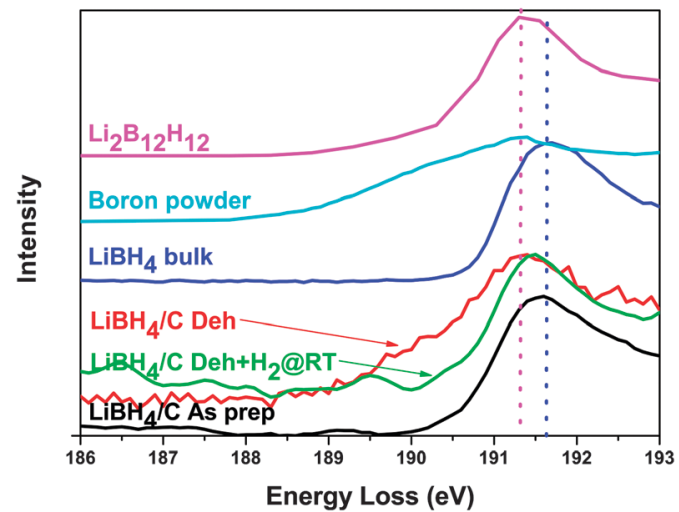

Fig. 2 B K-edge XRS spectra with energy loss range till $193 \mathrm{eV}$ of: $\mathrm{LiBH}_{4}-$ $C$ as prepared (As prep, black), after de-hydrogenation (Deh, red) and after partial re-hydrogenation under 1 bar pressure of hydrogen flow (Deh + $\mathrm{H}_{2}$ (aRT, green) compared with the $\mathrm{B} \mathrm{K}$-edge XRS of the reference materials $\mathrm{LiBH}_{4}$ bulk (blue), boron powder (light blue) and $\mathrm{Li}_{2} \mathrm{~B}_{12} \mathrm{H}_{12}$ (magenta). The vertical blue and magenta dotted lines refer to the maximum of $\mathrm{LiBH}_{4}$ bulk (blue) and $\mathrm{Li}_{2} \mathrm{~B}_{12} \mathrm{H}_{12}$ (magenta) respectively.

based on Fig. 1 and in that sense $\mathrm{LiBH}_{4}$ has disappeared and dehydrogenation leads to a shifted peak, in other words to a modified material where boron is more negatively (or less positively) charged.

Comparing the B K-edge XRS of the $\mathrm{LiBH}_{4}-\mathrm{C}$ deh (red) with the bulk $\mathrm{LiBH}_{4}$ (blue), $\mathrm{Li}_{2} \mathrm{~B}_{12} \mathrm{H}_{12}$ (magenta) and boron powder (light blue) shows that $\mathrm{LiBH}_{4}-\mathrm{C}$ deh contains boron and/or $\mathrm{Li}_{2} \mathrm{~B}_{12} \mathrm{H}_{12}$. Bulk $\mathrm{LiBH}_{4}$ is generally believed to decompose according to eqn (2a) and $(2 \mathrm{~b}):{ }^{25-28}$

$$
\begin{gathered}
12 \mathrm{LiBH}_{4} \rightarrow \mathrm{Li}_{2} \mathrm{~B}_{12} \mathrm{H}_{12}+10 \mathrm{LiH}+13 \mathrm{H}_{2} \\
\mathrm{Li}_{2} \mathrm{~B}_{12} \mathrm{H}_{12} \rightarrow 2 \mathrm{LiH}+12 \mathrm{~B}+5 \mathrm{H}_{2}
\end{gathered}
$$

In the case of nanoconfined $\mathrm{LiBH}_{4}$, lithium intercalation in the graphitic carbon has been reported, ${ }^{11,12,19,29}$ therefore lithium could be stabilized, leading to the following possible decomposition reactions:

$$
\begin{gathered}
12 \mathrm{LiBH}_{4}+\mathrm{XC} \rightarrow 10 \mathrm{LiC}_{x}+\mathrm{Li}_{2} \mathrm{~B}_{12} \mathrm{H}_{12}+18 \mathrm{H}_{2} \\
\mathrm{LiBH}_{4}+\mathrm{XC} \rightarrow \mathrm{LiC}_{x}+\mathrm{B}+2 \mathrm{H}_{2}
\end{gathered}
$$

Note that for reactions (3a) and (3b), $\mathrm{LiC}_{x}$ represents intercalated lithium and does not imply the formation of $\mathrm{Li}-\mathrm{C}$ bonds.

It is clear that the B K-edge XRS spectrum of $\mathrm{LiBH}_{4}-\mathrm{C}$ deh (Fig. 2, red) does not completely match either the B K-edge XRS of Boron powder (light blue) or the $\mathrm{Li}_{2} \mathrm{~B}_{12} \mathrm{H}_{12}$ (magenta) reference materials but the B K-edge XRS spectrum of $\mathrm{LiBH}_{4}-\mathrm{C}$ deh seems a combination of both materials. To estimate the fraction of both materials in the de-hydrogenated sample, the B K-edge XRS spectra of the different reference materials were areanormalized to their boron content with the area below the XRS curves as mentioned and shown in the ESI $\dagger$ (Fig. S5). The slope of the first peak in the $\mathrm{B}$ K-edge of $\mathrm{LiBH}_{4}-\mathrm{C}$ deh is strongly linked to the content of boron powder and the height of the XRS peak is connected to the $\mathrm{Li}_{2} \mathrm{~B}_{12} \mathrm{H}_{12}$ reference. Based on the relative combinations of the two references, all the ranges between $20 \%$ and $80 \%$ of boron and $\mathrm{Li}_{2} \mathrm{~B}_{12} \mathrm{H}_{12}$ show reasonable 


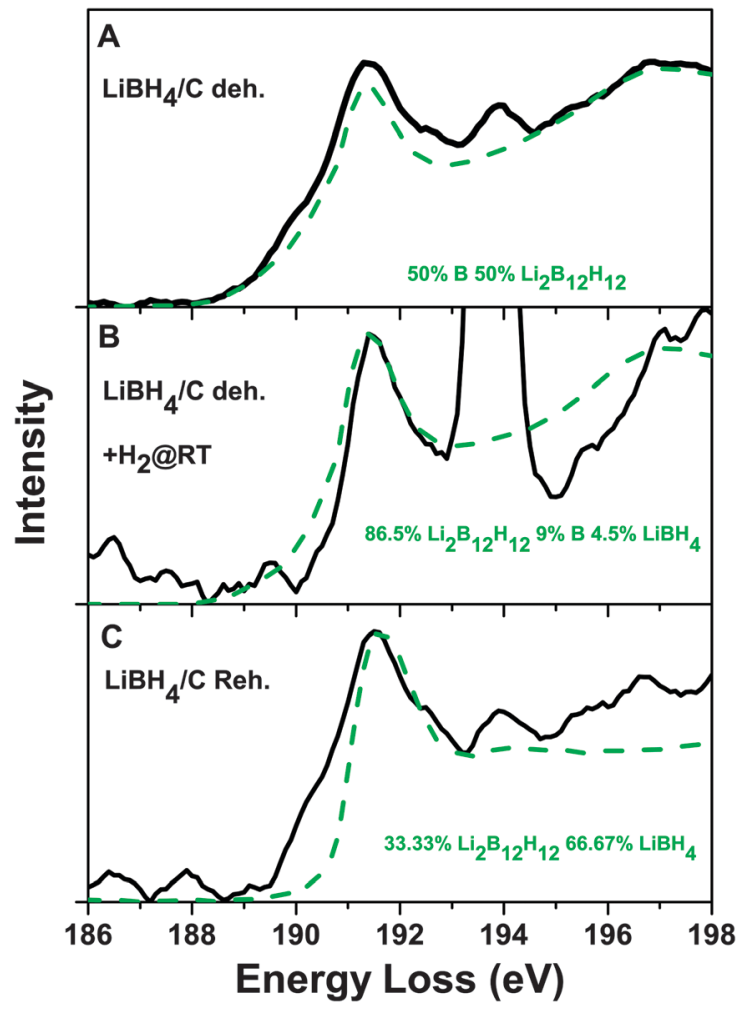

Fig. 3 Fits from the deconvolution of the $\mathrm{B}$ K-edge XRS of (A) $\mathrm{LiBH}_{4}-\mathrm{C}$ deh, (B) $\mathrm{LiBH}_{4}-\mathrm{C}$ deh $+\mathrm{H}_{2} \mathrm{aRT}$ and (C) $\mathrm{LiBH}_{4}-\mathrm{C}$ Reh. Black lines correspond to the experimental $\mathrm{B} \mathrm{K}$-edge XRS of the $\mathrm{LiBH}_{4}-\mathrm{C}$ at different points in the re-hydrogenation process and green dashed lines are the best convolution fit with their different percentages of reference materials. More deconvolution results are shown in the ESI $\dagger$ (Fig. S14).

agreement with the B K-edge XRS of $\mathrm{LiBH}_{4}-\mathrm{C}$ deh (Fig. 3A) with the best fit shown as green dashed line $(50 \%$ boron and $50 \% \mathrm{Li}_{2} \mathrm{~B}_{12} \mathrm{H}_{12}$ ). We estimate from the $\mathrm{B}$ K-edge XRS that there is $50 \pm 30 \%$ of boron and $50 \% \pm 30 \%$ of $\mathrm{Li}_{2} \mathrm{~B}_{12} \mathrm{H}_{12}$ present in the $\mathrm{LiBH}_{4}-\mathrm{C}$ deh sample. For an assignment with smaller error bars we might have to consider the Li K-edge XRS deconvolution of $\mathrm{LiBH}_{4}-\mathrm{C}$ deh as well (see next section). Note that the presence of both $\mathrm{B}$ and $\mathrm{Li}_{2} \mathrm{~B}_{12} \mathrm{H}_{12}$ in the de-hydrogenated sample is in line with the fact that only limited lithium intercalation (lithium insertion) occurs in this graphitic carbon, ${ }^{11,30}$ so a combination of reactions (2a), (2b) and (3a), (3b) could be expected. Another possibility is that the $25 \mathrm{wt} \% \mathrm{LiBH}_{4}-\mathrm{C}$ contains a small amount of bulk $\mathrm{LiBH}_{4}$ (that did not go into the pores of the nanoporous carbon and thus is not nanoconfined), which does not completely de-hydrogenate under the present temperature conditions and that is why we observe more $\mathrm{Li}_{2} \mathrm{~B}_{12} \mathrm{H}_{12}$ than expected based on reaction eqn (3a). One can imagine that $\mathrm{LiBH}_{4}$ close to the carbon surface could be de-hydrogenated following (3b) while the remaining $\mathrm{LiBH}_{4}$ will de-hydrogenate either according to reaction eqn (2a) and (2b) or with a ratio of 12:1 for $\mathrm{LiBH}_{4}$ to carbon via reaction eqn (3a). The Li K-edge XRS could as well be informative on this aspect, since whenever boron is present also $\mathrm{LiH}$ or $\mathrm{Li}$ in some form should be present.
In addition to de-hydrogenation ex situ, we performed in situ partial re-hydrogenation of the de-hydrogenated sample under 1 bar of hydrogen pressure, and $400{ }^{\circ} \mathrm{C}$ for half an hour and measure the $\mathrm{B}$ and Li K-edge XRS of the in situ partially re-hydrogenated products after cooling down. The green line in Fig. 2 presents the B K-edge XRS spectrum of $\mathrm{LiBH}_{4}-\mathrm{C}$ deh that was subsequently partially re-hydrogenated in situ $\left(\mathrm{LiBH}_{4}-\mathrm{C}\right.$ deh $+\mathrm{H}_{2}$ @RT). Note the similarity with the $\mathrm{LiBH}_{4}-\mathrm{C}$ As prep (black line), During the in situ partial re-hydrogenation, the B K-edge XRS peak at $194 \mathrm{eV}$ assigned to oxidic boron increases even more (Fig. 3B, black).

That means that the reaction to form $\mathrm{LiBO}_{2}$ continues during the re-hydrogenation process, which is expected as the de-hydrogenated sample is even more reactive and sensitive to oxygen. This also affects the accuracy of the B K-edge measurements as the background becomes higher relative to the main peak close to $191.5 \mathrm{eV}$ (Fig. 2, green line). Nevertheless, the start of the band around 190-191 eV shifts back to higher energy loss values for the B K-edge XRS of $\mathrm{LiBH}_{4}-\mathrm{C}$ deh $+\mathrm{H}_{2} @ \mathrm{Q} \mathrm{RT}$. The distinct $\mathrm{B}$ K-edge slope of boron powder is almost lacking for the $\mathrm{LiBH}_{4}-\mathrm{C}$ deh $+\mathrm{H}_{2}$ @RT. The deconvolution of $\mathrm{LiBH}_{4}-\mathrm{C}$ deh + $\mathrm{H} @ \mathrm{RT}$ with the best fit is shown in Fig. 3B. Based on this deconvolution result there is about $10 \%$ boron present, a majority of $(>80 \%) \mathrm{Li}_{2} \mathrm{~B}_{12} \mathrm{H}_{12}$ and a little amount $(\sim 5 \%)$ of $\mathrm{LiBH}_{4}$. This result seems to suggest that with 1 bar of hydrogen, partial re-hydrogenation to $\mathrm{LiBH}_{4}$ can be achieved for these nanoconfined $\mathrm{LiBH}_{4}-\mathrm{C}$ samples. It is likely that this occurs with the reverse route of reaction eqn (3b). While a large proportion of the boron is not present anymore, it is also likely that the reverse route of reaction eqn (2b) occurred. This implies that $\mathrm{LiBH}_{4}-\mathrm{C}$ follows the same de-/re-hydrogenation route as bulk $\mathrm{LiBH}_{4}$, but that in addition there is a more direct way for re-hydrogenation to $\mathrm{LiBH}_{4}$ (reverse route of reaction eqn (3b)) for the $\mathrm{LiBH}_{4}$ confined in nanoporous carbon compared to de- and re-hydrogenation of bulk $\mathrm{LiBH}_{4}$.

The B K-edge XRS of the ex situ re-hydrogenated sample, $\mathrm{LiBH}_{4}-\mathrm{C}$ reh (Fig. 3C, black line; full B K-edge range ESI, $\dagger$ Fig. S8) relates to a combination of the $\mathrm{B}$ K-edge XRS spectra of the $\mathrm{LiBH}_{4}-\mathrm{C}$ as prep and $\mathrm{LiBH}_{4}-\mathrm{C}$ deh spectra. Note that the ex situ re-hydrogenation was done by heating the de-hydrogenated sample at 60 bar of $\mathrm{H}_{2}$ and $325{ }^{\circ} \mathrm{C}$ for $3 \mathrm{hrs}$ while the partial in situ re-hydrogenation was done by heating the in situ cell de-hydrogenated samples to $370{ }^{\circ} \mathrm{C}$ under a constant $10 \mathrm{ml}$ flow of 1 bar $\mathrm{H}_{2}$. After deconvolution analysis of the $\mathrm{LiBH}_{4}-\mathrm{C}$ reh, the best fit (blue line) is shown in Fig. 3C. It is estimated that the ex situ re-hydrogenated $\mathrm{LiBH}_{4}-\mathrm{C}$ contains $20 \pm 10 \%$ boron, $40 \pm 20 \% \mathrm{Li}_{2} \mathrm{~B}_{12} \mathrm{H}_{12}$ and $40 \pm 20 \% \mathrm{LiBH}_{4}$. This implies that the sample has not been fully rehydrogenated to $\mathrm{LiBH}_{4}$ based on the B K-edge XRS of $\mathrm{LiBH}_{4}-\mathrm{C}$ reh. Formation of $40 \pm 20 \% \mathrm{LiBH}_{4}$ after ex situ rehydrogenation is also in-line with the fact that only about $6.5 \mathrm{wt} \% \mathrm{H}_{2}$ per $\mathrm{g} \mathrm{LiBH}_{4}$ was realised from the ex situ rehydrogenated sample during the second cycle of hydrogen release experiment conducted ex situ. ${ }^{30}$

\section{Li K-edge XRS of $\mathrm{LiBH}_{4}-\mathrm{C}$}

The Li K-edge XRS spectra of the $\mathrm{LiBH}_{4}-\mathrm{C}$ as prep (pink line) and $\mathrm{LiBH}_{4}-\mathrm{C}$ deh (brown line) are shown in Fig. 4 together with $\mathrm{LiBO}_{2}, \mathrm{Li}, \mathrm{LiH}$ and $\mathrm{LiBH}_{4}$ references. The Li-LiH-LiBH 4 series 


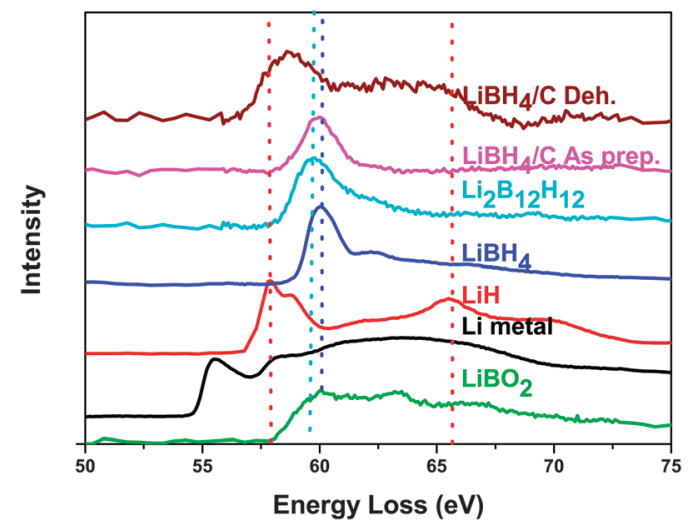

Fig. 4 Lithium K-edge XRS spectra of the reference materials bulk $\mathrm{LiBO}_{2}$ powder (green), Li metal (black), $\mathrm{LiH}$ powder (red), bulk $\mathrm{LiBH}_{4}$ powder (blue) and $\mathrm{Li}_{2} \mathrm{~B}_{12} \mathrm{H}_{12}$ (light blue) in comparison with the $\mathrm{LiBH}_{4}-\mathrm{C}$ as prepared $\left(\mathrm{LiBH}_{4}-\mathrm{C}\right.$ as prep, pink) and the de-hydrogenated $\mathrm{LiBH}_{4}-\mathrm{C}$ $\left(\mathrm{LiBH}_{4}-\mathrm{C}\right.$ deh, brown). The main peaks of $\mathrm{LiBH}_{4}, \mathrm{LiH}$ and $\mathrm{Li}_{2} \mathrm{~B}_{12} \mathrm{H}_{12}$ are indicated with dotted lines corresponding to the color of the XRS

shows its first peak shifting to higher energies indicating an increased Li charge/valence. According to our knowledge, this is the first time that the $\mathrm{Li} \mathrm{K}$ edge of $\mathrm{LiH}$ is published, which is possible due to the in situ reactor that can prevent the oxidation or decomposition of $\mathrm{LiH}$ in (humid) air.

The Li K-edge XRS spectrum of $\mathrm{LiBH}_{4}-\mathrm{C}$ as prep (Fig. 4, pink line) agrees well with the Li K-edge XRS spectrum of the $\mathrm{LiBH}_{4}$ bulk reference, supporting the B K-edge assignment above for $\mathrm{LiBH}_{4}-\mathrm{C}$ as prep (Fig. 1) and the assignment in an earlier report. ${ }^{25}$ The $\mathrm{LiBH}_{4}-\mathrm{C}$ deh (Fig. 4, brown line) has a band which is slightly broader than for the $\mathrm{LiH}$ reference, but at first glance it seems that the Li K-edge XRS spectrum of $\mathrm{LiBH}_{4}-\mathrm{C}$ deh contains all the features of the XRS spectrum of $\mathrm{LiH}$. According to the comparison between the Li K-edge XRS spectrum of $\mathrm{LiBH}_{4}-\mathrm{C}$ deh and the Li K-edge XRS of lithium, there is no metallic lithium present in the $\mathrm{LiBH}_{4}-\mathrm{C}$ deh sample, which would suggest that the de-hydrogenation reaction did not go further than the formation of $\mathrm{B}$ and $\mathrm{LiH}$ (eqn (2a) and (2b)). However on the contrary, about $15 \mathrm{wt} \% \mathrm{H}_{2}$ was released from the sample during an ex situ hydrogen release measurement conducted under similar conditions, but with Ar carrier gas instead of He (see e.g., ref. 30). This would suggest further decomposition of some part of $\mathrm{LiH}$ or $\mathrm{Li}_{2} \mathrm{~B}_{12} \mathrm{H}_{12}$ into $\mathrm{Li}$ or intercalated $\mathrm{Li}$ according to eqn (3a) or (3b). Furthermore, using XRD, reversible Li intercalation has been demonstrated earlier in these samples. ${ }^{11,30}$ Therefore if reaction (3a) or (3b) did occur to some extent, the lithium is likely intercalated in the carbon. Unfortunately, we do not know how the Li K-edge XRS features of intercalated lithium will look like in the present carbon nanoframework and therefore we do not know its features in Li XRS, but we expect that this is also present in Li XRS spectrum of the $\mathrm{LiBH}_{4}-\mathrm{C}$ deh due to the broader band area between 60 and $62 \mathrm{eV}$. That area cannot be assigned to any of the reference materials measured by us, but the Li K-edge EELS spectrum of intercalated lithium of Wang et al. ${ }^{31}$ shows qualitative agreement with these unassigned features. It seems there is also a partial contribution of $\mathrm{Li}_{2} \mathrm{~B}_{12} \mathrm{H}_{12}$ in the de-hydrogenated sample. The Li K-edge XRS spectrum of $\mathrm{LiBH}_{4}-\mathrm{C}$ deh also should show some $\mathrm{LiBO}_{2}$ (green line) features as we saw before in the B K-edge, but it is difficult to make the oxide influence quantitative, because the $\mathrm{Li}$ K-edge XRS of $\mathrm{LiBO}_{2}$ does not contain sharp features. As there is no reference material for the intercalated lithium in the nanoporous carbon used here (which might be slightly different from ref. 31), it is not straightforward to perform a proper deconvolution of the $\mathrm{Li}$ K-edge XRS spectrum of $\mathrm{LiBH}_{4}-\mathrm{C}$ deh. However as a careful guess the Li K-edge XRS of $\mathrm{LiBH}_{4}-\mathrm{C}$ deh can be deconvoluted into $70 \pm 30 \%$ of $\mathrm{LiH}$ and $20 \pm 30 \%$ of $\mathrm{Li}_{2} \mathrm{~B}_{12} \mathrm{H}_{12}$, while we consider an extra error due the possibility that there can be $10 \pm 10 \%$ of intercalated lithium present, also in line with results obtained based on previous $\mathrm{XRD}^{30}$ and ${ }^{7} \mathrm{Li}$ NMR results. ${ }^{19}$

In the Li K-edge XRS spectra of the $\mathrm{LiBH}_{4}-\mathrm{C}$ deh $+\mathrm{H}_{2} @ \mathrm{RT}$ and $\mathrm{LiBH}_{4}-\mathrm{C}$ reh (ESI, $\dagger$ Fig. $\mathrm{S} 10 \mathrm{~B}$ ), the deconvolution is possible again, since the feature between $60-62 \mathrm{eV}$ disappeared and apparently all the intercalated lithium reacted to something else under 1 or 50 bar of hydrogen. The result of the deconvolution of $\mathrm{LiBH}_{4}-\mathrm{C}$ deh $+\mathrm{H}_{2}$ @RT (ESI, $\dagger$ Fig. S12) is: $5 \pm 3 \% \mathrm{LiH}, 95 \pm 3 \%$ $\mathrm{Li}_{2} \mathrm{~B}_{12} \mathrm{H}_{12}$ and $\sim 2 \pm 3 \% \mathrm{LiBH}_{4}$, which is consistent with the $>80 \% \mathrm{Li}_{2} \mathrm{~B}_{12} \mathrm{H}_{12}$ and $5 \% \mathrm{LiBH}_{4}$ deconvolution results from the B K-edge XRS of $\mathrm{LiBH}_{4}-\mathrm{C}$ deh $+\mathrm{H}_{2}$ @RT (Fig. 3B).

Concerning the deconvolution of the Li K-edge XRS of the $\mathrm{LiBH}_{4}-\mathrm{C}$ reh in $20 \pm 20 \% \mathrm{LiH}, 20 \pm 20 \% \mathrm{Li}_{2} \mathrm{~B}_{12} \mathrm{H}_{12}$ and $60 \pm 20 \%$ of $\mathrm{LiBH}_{4}$ (ESI, $\dagger$ Fig. S13) there is agreement with the B K-edge XRS deconvolution assignments concerning amounts of $\mathrm{LiBH}_{4}$ and $\mathrm{Li}_{2} \mathrm{~B}_{12} \mathrm{H}_{12}$, but there is an unexpected increase in amount of $\mathrm{LiH}$ compared to the partially re-hydrogenated sample $\mathrm{LiBH}_{4}-\mathrm{C}$ deh $+\mathrm{H}_{2}$ @RT.

\section{Discussion}

The de-hydrogenation of $\mathrm{LiBH}_{4}$ to $\mathrm{Li}_{2} \mathrm{~B}_{12} \mathrm{H}_{12}$, boron, $\mathrm{LiH}$ and intercalated lithium and re-hydrogenation back to $\mathrm{LiBH}_{4}$ can be followed with the resemblance of the 190-191 eV band in the $\mathrm{B}$ K-edge XRS and the bands between 58-60 and 60-62 eV (intercalated lithium) in the Li K-edge XRS in comparison to spectra of reference materials. The XRS results provide evidence that the nanoconfined material partially re-hydrogenates to $\mathrm{LiBH}_{4}$ under 1 bar of hydrogen, but it remains only a small percentage of the overall amount of compounds (See Table 1, fourth column).

Combining the information from the Li and B K-edge XRS, it can be concluded that the nanoconfined $\mathrm{LiBH}_{4}-\mathrm{C}$ de-hydrogenates into 50 to $80 \%$ boron and $\mathrm{LiH}$ and 20 to $50 \%$ of $\mathrm{Li}_{2} \mathrm{~B}_{12} \mathrm{H}_{12}$ and there is likely some amount of lithium intercalated in the carbon (estimate $\sim 10 \%$ ). Since we do not see any metallic lithium, but only intercalated lithium or lithium compounds that still contain an amount of hydrogen ( $\mathrm{LiH}$ and $\mathrm{Li}_{2} \mathrm{~B}_{12} \mathrm{H}_{12}$ ) we underline the suggestion that nanoporous carbon material stabilizes the $\mathrm{Li}$ de-hydrogenation products (and in particular metallic-like lithium) as reported previously. ${ }^{12,13}$ The unknown feature in the Li K-edge, presently assigned to intercalated lithium $\left(\mathrm{LiC}_{x}\right)$ disappears with (partial) re-hydrogenation. The deconvolution 
Table 1 Summary of deconvolution results of the $B$ and Li K-edge XRS of $\mathrm{LiBH}_{4}-\mathrm{C}$ as prep., deh, deh $+\mathrm{H}_{2} @ \mathrm{aRT}$ and reh

\begin{tabular}{|c|c|c|c|c|}
\hline XRS & As prep & Deh & Part. Reh. & Reh. \\
\hline B K-edge & $\sim 100 \% \mathrm{LiBH}_{4}$ & $\begin{array}{l}50 \pm 30 \% \text { Boron, } \\
50 \pm 30 \% \mathrm{Li}_{2} \mathrm{~B}_{12} \mathrm{H}_{12}\end{array}$ & $\begin{array}{l}10 \pm 10 \% \text { boron, } \\
>80 \pm 10 \% \mathrm{Li}_{2} \mathrm{~B}_{12} \mathrm{H}_{12} \\
\sim 5 \pm 5 \% \mathrm{LiBH}_{4}\end{array}$ & $\begin{array}{l}20 \pm 10 \% \text { boron, } \\
40 \pm 20 \% \mathrm{Li}_{2} \mathrm{~B}_{12} \mathrm{H}_{12} \\
40 \pm 20 \% \mathrm{LiBH}_{4}\end{array}$ \\
\hline Li K-edge & $\sim 100 \% \mathrm{LiBH}_{4}$ & $\begin{array}{l}70 \pm 30 \% \mathrm{LiH} \\
20 \pm 30 \% \mathrm{Li}_{2} \mathrm{~B}_{12} \mathrm{H}_{12} \\
\sim 10 \pm 10 \% \mathrm{LiC}_{x}\end{array}$ & $\begin{array}{l}5 \pm 3 \% \mathrm{LiH} \\
95 \pm 3 \% \mathrm{Li}_{2} \mathrm{~B}_{12} \mathrm{H}_{12} \\
\sim 2 \pm 3 \% \mathrm{LiBH}_{4}\end{array}$ & $\begin{array}{l}20 \pm 20 \% \mathrm{LiH} \\
20 \pm 20 \% \mathrm{Li}_{2} \mathrm{~B}_{12} \mathrm{H}_{12} \\
60 \pm 20 \% \mathrm{LiBH}_{4}\end{array}$ \\
\hline
\end{tabular}

analysis of the $\mathrm{B}$ K-edge XRS of $\mathrm{LiBH}_{4}-\mathrm{C}$ that was partially re-hydrogenated $\left(\mathrm{LiBH}_{4}-\mathrm{C}\right.$ deh $\left.+\mathrm{H}_{2} @ \mathrm{RT}\right)$ demonstrated with reference to the $\mathrm{LiBH}_{4}-\mathrm{C}$ deh, that there is a lower boron content $(<10 \pm 10 \%)$, some formation $(2 \%)$ of $\mathrm{LiBH}_{4}$ in this case and the major component is $\mathrm{Li}_{2} \mathrm{~B}_{12} \mathrm{H}_{12}$. The deconvolution of the Li K-edge XRS of $\mathrm{LiBH}_{4}-\mathrm{C}$ deh $+\mathrm{H}_{2}$ @RT supports that the formation of about $2-5 \%$ of $\mathrm{LiBH}_{4}$, and also suggests that the major component is $\mathrm{Li}_{2} \mathrm{~B}_{12} \mathrm{H}_{12}$.

Based on both the Li K-edge and B K-edge XRS of $\mathrm{LiBH}_{4}-\mathrm{C}$ reh, it is estimated that the nanoconfined $\mathrm{LiBH}_{4}$ after full de- and re-hydrogenation ex situ consists of approximately $60 \%$ of $\mathrm{LiBH}_{4}, 20-30 \%$ of $\mathrm{Li}_{2} \mathrm{~B}_{12} \mathrm{H}_{12}, 10 \%$ of boron and $10-20 \%$ of $\mathrm{LiH}$. Interestingly, these numbers are in line with the amount of $\mathrm{H}_{2}$ released from the rehydrogenated sample during ex situ temperature programmed hydrogen release measurements.

In summary the $\mathrm{B}$ and $\mathrm{Li}$ K-edge XRS spectra show that $\mathrm{LiBH}_{4}-\mathrm{C}$ changes from $\mathrm{LiBH}_{4}$ to a combination of intercalated lithium, $\mathrm{LiH}$, and $\mathrm{B}$ and some $\mathrm{Li}_{2} \mathrm{~B}_{12} \mathrm{H}_{12}$ and in the first re-hydrogenation step (under a small hydrogen pressure) a small amount of $\mathrm{LiBH}_{4}$ is reformed, but mainly $\mathrm{Li}_{2} \mathrm{~B}_{12} \mathrm{H}_{12}$ is formed and after full re-hydrogenation at least $60 \%$ of $\mathrm{LiBH}_{4}$ is reformed, while still some amounts of $\mathrm{LiH}, \mathrm{B}$ and $\mathrm{Li}_{2} \mathrm{~B}_{12} \mathrm{H}_{12}$ are present. Thus XRS shows that partial re-hydrogenation of $\mathrm{LiBH}_{4}$ is possible under the in situ 1 bar $\mathrm{H}_{2}$, which is most likely due to the recombination of the $\mathrm{LiC}_{x}$ and some $\mathrm{B}$ in the presence of $\mathrm{H}_{2}$. As well under the ex situ full re-hydrogenation conditions it is observed that there is no complete re-hydrogenation which has been reported before. ${ }^{12}$ Remaining questions are: what does the increase of the amount of $\mathrm{LiH}$ between partial re-hydrogenation and full re-hydrogenation conditions mean? Is this due to the much stronger stability of $\mathrm{LiH}$ compared to the other intermediate and final phases? And: is there a change in the second de- and re-hydrogenation cycle?

We mentioned in the experimental section that also the carbon (C) K-edge XRS of the $\mathrm{LiBH}_{4}-\mathrm{C}$ materials was measured under the different as prepared, de- and re-hydrogenation conditions. We do not see clear differences in the C K-edge XRS (shown in the ESI, $\uparrow$ Fig. S16) meaning that the carbon material is stable under all the different conditions or that the differences are smaller than the obtained $\mathrm{C}$ K-edge XRS resolution.

As mentioned in the introduction, $\mathrm{B}$ and $\mathrm{C}$ K-edge XRS measurements were also performed on nanoconfined sodium borohydride $\left(\mathrm{NaBH}_{4}-\mathrm{C}\right)$ under different de- and re-hydrogenation conditions (Fig. S17, S19 and S21, ESI $\dagger$ ). Similar to nanoconfined $\mathrm{LiBH}_{4}$, we also saw a shift in the B K-edge energy of the dehydrogenated nanocomposites as compared to the sample as prepared or the $\mathrm{NaBH}_{4}$ bulk (Fig. S19, ESI $\dagger$ ), suggesting the formation of $\mathrm{Na}_{2} \mathrm{~B}_{12} \mathrm{H}_{12}$ as earlier reported (for example ref. 10). Also slight shift towards the original value occurred in the ex situ rehydrogenated samples due to partial reversibility of these samples. ${ }^{10,30}$ However detailed quantification of the phases was not possible due to the lack of data on other standard reference materials like $\mathrm{Na}_{2} \mathrm{~B}_{12} \mathrm{H}_{12}$ during the XRS measurements. Nevertheless, these results demonstrate that XRS can be applied as well for the study of the decomposition of other borohydrides and B-based hydrogen storage materials.

\section{Conclusions}

Using X-Ray Raman Spectroscopy it was found that the spectrum of $\mathrm{LiBH}_{4}-\mathrm{C}$ is similar to the spectrum of bulk $\mathrm{LiBH}_{4}$ powder, in agreement with other experiments. ${ }^{11,12}$ During and after de-hydrogenation, the $\mathrm{LiBH}_{4}-\mathrm{C}$ decomposes mainly in $\mathrm{LiH}$ and boron and there is also a substantial amount of $\mathrm{Li}_{2} \mathrm{~B}_{12} \mathrm{H}_{12}$. In addition we observed a signature of intercalated $\mathrm{Li}$ in carbon, based on features in the Li K-edge XRS that resemble the Li K-edge EELS features of intercalated lithium. ${ }^{31}$ During re-hydrogenation, the first step (observed under 1 bar of hydrogen pressure) suggest the formation of $\mathrm{LiH}$ and $\mathrm{Li}_{2} \mathrm{~B}_{12} \mathrm{H}_{12}$ and already a small amount of $\mathrm{LiBH}_{4}$ formed from the combination of intercalated Lithium in carbon, boron and hydrogen. This suggests that the nanoconfined $\mathrm{LiBH}_{4}$ has a different hydrogen re-absorption mechanism (reverse reaction of eqn (3b)) which is different from that of bulk de-hydrogenated $\mathrm{LiBH}_{4}$, since under normal conditions the presence of $\mathrm{LiBH}_{4}$ is unexpected under 1 bar of hydrogen pressure. After full re-hydrogenation, there is mainly $\mathrm{LiBH}_{4}$ and there are minor contributions from $\mathrm{Li}_{2} \mathrm{~B}_{12} \mathrm{H}_{12}, \mathrm{LiH}$ and boron still present. All these conclusions are based on the combined deconvolution of the B and Li K-edge XRS.

Summarized in general, the results presented here on the XRS of nanoconfined $\mathrm{LiBH}_{4}$ and $\mathrm{NaBH}_{4}$ in the ESI, $\dagger$ combined with the XRS of reference materials, shows that XRS may soon become an important tool for characterizing the different phases of the complex hydrogen storage materials based on $\mathrm{B}$ and other light elements such as $\mathrm{Li}$ and $\mathrm{Na}$. This is particularly very useful for the characterization of the often non-crystalline phases present in nano-confined hydrogen storage materials.

\section{Acknowledgements}

PSM and FMFdG acknowledge NWO- CW/VICI and PN acknowledge NWO-CW/VIDI 016.072.316 for financial support. We would like to thank the Stanford Synchrotron Radiation Lightsource 
(SSRL) for beamtime. The SSRL is a National User Facility operated by Stanford University on behalf of the U.S. Department of Energy, Office of Basic Energy Sciences. Timcal Switzerland is acknowledged for the provision of the graphite and porous carbon.

\section{Notes and references}

1 Y. Nakamori, K. Miwa, H. W. Li, N. Ohba, S. I. Towata and S. I. Orimo, MRS Proceedings, 2006, 971, 0971-Z02-01, DOI: 10.1557/PROC-0971-Z02-01.

2 H. W. Li, Y. G. Yan, S. Orimo, A. Zuttel and C. M. Jensen, Energies, 2011, 4, 185-214.

3 P. Martelli, R. Caputo, A. Remhof, P. Mauron, A. Borgschulte and A. Züttel, J. Phys. Chem. C, 2010, 114, 7173-7177.

4 P. Mauron, F. Buchter, O. Friedrichs, A. Remhof, M. Bielmann, C. N. Zwicky and A. Zuttel, J. Phys. Chem. B, 2008, 112, 906-910.

5 M. Aoki, K. Miwa, T. Noritake, G. Kitahara, Y. Nakamori, S. I. Orimo and S. Towata, Appl. Phys. A: Mater. Sci. Process., 2005, 80, 1409.

6 M. Au, A. Jurgensen and K. Zeigler, J. Phys. Chem. B, 2006, 110, 26482.

7 Z. Z. Fang, X. D. Kang, P. Wang and H. M. Cheng, J. Phys. Chem. C, 2008, 112, 17023.

8 A. F. Gross, J. J. Vajo, S. L. Van Atta and G. L. Olson, J. Phys. Chem. C, 2008, 112, 5651-5657.

9 X. D. Kang, P. Wang, L. P. Ma and H. M. Cheng, Appl. Phys. A: Mater. Sci. Process., 2007, 89, 963.

10 P. Ngene, R. Van Den Berg, M. H. W. Verkuijlen, K. P. De Jong and P. E. De Jongh, Energy Environ. Sci., 2011, 4, 4108-4115.

11 P. Ngene, R. Van Zwienen and P. E. De Jongh, Chem. Commun., 2010, 46, 8201-8203.

12 P. Ngene, M. H. W. Verkuijlen, Q. Zheng, J. Kragten, P. J. M. van Bentum, J. H. Bitter and P. E. de Jongh, Faraday Discuss., 2011, 151, 47.

13 G. L. Xia, X. B. Yu, Z. Q. Zou, Z. L. Li, Z. Wu, D. L. Akins and H. Yang, Chem. Commun., 2008, 5740.

14 J. Xu, X. B. Yu, Z. Q. Zou, Z. L. Li, Z. Wu, D. L. Akins and H. Yang, Chem. Commun., 2008, 5470.

15 M. L. Christian and K.-F. Aguey-Zinsou, ACS Nano, 2012, 6, 7739 .
16 D. B. Ravnsbaek, Y. Filinchuk, R. Cerný and T. R. Jensen, Z. Kristallogr. - Cryst. Mater., 2010, 225, 557.

17 A. Remhof, P. Mauron, A. Züttel, J. P. Embs, Y. Lodziana, A. J. Ramirez-Cuesta, P. Ngene and P. E. de Jongh, J. Phys. Chem. C, 2013, 117, 3789.

18 A. Remhof, Z. Lodziana, P. Martelli, O. Friedrichs, A. Züttel, A. V. Skripov, J. P. Embs and T. Strässle, Phys. Rev. B: Condens. Matter Mater. Phys., 2010, 81, 214304.

19 M. H. W. Verkuijlen, P. Ngene, D. W. de Kort, C. Barré, A. Nale, E. R. H. van Eck, P. J. M. van Bentum, P. E. de Jongh and A. P. M. Kentgens, J. Phys. Chem. C, 2012, 116, 22169.

20 P. S. Miedema, P. Ngene, A. M. J. Van Der Eerden, T. C. Weng, D. Nordlund, D. Sokaras, R. Alonso-Mori, A. Juhin, P. E. De Jongh and F. M. F. De Groot, Phys. Chem. Chem. Phys., 2012, 14, 5581-5587.

21 U. Bergmann, P. Glatzel and S. P. Cramer, Microchem. J., 2002, 71, 221-230.

22 L. He, H.-W. Li, S.-J. Hwang and E. Akiba, J. Phys. Chem. C, 2014, 118, 6084-6089.

23 O. Friedrichs, A. Remhof, S. J. Hwang and A. Zuttel, Chem. Mater., 2010, 22, 3265-3268.

24 D. Sokaras, D. Nordlund, T.-C. Weng, R. Alonso-Mori, P. Velikov, D. Wenger, A. Garachtchenko, M. George, V. Borzenets, B. C. Johnson, Q. Qian, T. Rabedeau and U. Bergmann, Rev. Sci. Instrum., 2012, 83, 043112.

25 S. I. Orimo, Y. Nakamori, N. Ohba, K. Miwa, M. Aoki, S. I. Towata and A. Züttel, Appl. Phys. Lett., 2006, 89, 021920.

26 S. J. Hwang, R. C. Bowman Jr, J. W. Reiter, J. Rijssenbeek, G. L. Soloveichik, J. C. Zhao, H. Kabbour and C. C. Ahn, J. Phys. Chem. C, 2008, 112, 3164-3169.

27 S. Kato, M. Bielmann, A. Borgschulte, V. Zakaznova-Herzog, A. Remhof, S. I. Orimo and A. Züttel, Phys. Chem. Chem. Phys., 2010, 12, 10950.

28 Y. Yan, A. Remhof, S.-J. Hwang, H.-W. Li, P. Mauron, S.-i. Orimo and A. Zuttel, Phys. Chem. Chem. Phys., 2012, 14, 6514-6519.

29 P. Adelhelm and P. E. de Jongh, J. Mater. Chem., 2011, 21, 2417-2427.

30 P. Ngene, PhD thesis, Utrecht, 2012.

31 F. Wang, J. Graetz, M. S. Moreno, C. Ma, L. Wu, V. Volkov and Y. Zhu, ACS Nano, 2011, 5, 1190-1197. 